\title{
Ditryptophan Cross-Links as Novel Products of Protein Oxidation
}

\author{
Verônica Paviani, ${ }^{a}$ Gabriel T. Galdino, ${ }^{a}$ Janaina N. dos Prazeres, ${ }^{a}$ Raphael F. Queiroz ${ }^{b}$ \\ and Ohara Augusto*a
}

\author{
${ }^{a}$ Departamento de Bioquímica, Instituto de Química, Universidade de São Paulo, \\ Avenida Lineu Prestes, 748, 05508-000 São Paulo-SP, Brazil \\ ${ }^{b}$ Departamento de Ciências Naturais, Universidade Estadual do Sudoeste da Bahia, \\ 45083-900 Vitória da Conquista-BA, Brazil
}

\begin{abstract}
Protein oxidation is an unavoidable consequence of aerobic metabolism. The oxidation of most proteins residues is non-repairable and may affect protein structure and function. In particular, protein cross-links arising from oxidative modifications are presumably toxic to cells because they may accumulate and induce protein aggregation. However, most of these irreversible protein cross-links remain partially characterized. Up to very recently, ditryptophan cross-links (Trp-Trp), in particular, have been largely disregarded in the literature. Here, we briefly review studies showing that Trp-Trp cross-links can be formed in proteins exposed to a variety of oxidants. The challenges to fully characterize Trp-Trp cross-links are discussed as well as their potential roles in protein dysfunction and aggregation.
\end{abstract}

Keywords: ditryptophan, cross-links, protein oxidation, free radicals

\section{Protein Oxidation}

Free radicals and other oxidants are formed in living organisms by oxidation-reduction processes, which occur continuously during metabolism and through interactions with the environment. Organisms evolved enzymatic antioxidant defenses and the capability to use antioxidants from the diet to control the levels of these species. ${ }^{1,2}$ Nevertheless, under certain circumstances, the levels of radicals and oxidants increase, promoting the oxidation of biomolecules. Among them, proteins are the major targets, due to their high biological abundance and reactivity towards one- and two-electron oxidants. ${ }^{3-5}$ Protein residues most susceptible to oxidation are the sulfur-containing residues Cys and Met, and the aromatic residues His, Phe, Tyr, and Trp. In vivo, the oxidation of Cys and Met residues can be reversed by biological reductants with the assistance of enzymatic systems. In fact, the reversible oxidation of protein-Cys residues is emerging as a fundamental cell regulatory mechanism. ${ }^{2,6-8}$

The oxidation of all the other protein residues is irreversible, and includes several covalent modifications,

*e-mail: oaugusto@iq.usp.br

This paper is part of the PubliSBQ Special Issue "IUPAC-2017" (http://publi.sbq.org.br/). such as protein cleavage, carbonylation, nitration, hydroxylation, halogenation and protein cross-linking with other proteins, lipids, carbohydrates and nucleic acids. $^{3-5,9-11}$ These modifications result in protein fragmentation, loss of protein function, protein aggregation and/or altered protein turnover, leading to cell and tissue dysfunction and various human pathologies. To maintain cellular homeostasis, proteins irreversibly oxidized are targeted for degradation by the proteasomal and lysosomal degradation pathways. ${ }^{11,12}$ During aging and pathological conditions associated with oxidative stress, however, the levels of over-oxidized and cross-linked proteins accumulate because these species are poor substrates for the intracellular proteolytic systems. This may lead to protein aggregation, which is a hallmark of age-related diseases, such as neurodegenerative diseases, atherosclerosis and cataract. ${ }^{11,12}$ Therefore, the study of irreversible protein oxidation in vitro and in vivo is relevant to the understanding of the pathogenic mechanism of diseases that afflict the increasing aged human population.

The investigation of protein oxidation and aggregation also has commercial relevance due to the augmented number of protein pharmaceuticals reaching the market. These pharmaceuticals can degrade via multiple physical and chemical processes, including protein photo-oxidation 
and aggregation. ${ }^{13,14} \mathrm{~A}$ better knowledge of these processes is necessary to prevent degradation and to maintain the stability of protein pharmaceuticals.

Despite the potential of protein-protein cross-links constituting protein aggregation-prone intermediates, the chemical nature of these bonds remains only partially characterized. Among the reasons for this situation is the lack of bioinformatic tools to analyze LC-MS/MS (liquid chromatography tandem mass spectrometry) proteomic data related to protein-protein cross-links, ${ }^{15}$ although these tools are currently under development. An important example is the 3,3'-dityrosine cross-link (Tyr-Tyr) resulting from recombination of protein-tyrosyl radicals (P-Tyr'). This is the most investigated irreversible protein-protein cross-link and has been reported to occur under several pathological conditions. ${ }^{15-18}$ Nevertheless, Tyr-Tyr detection in biological samples has been based mainly on its intrinsic fluorescence and/or its reactivity towards antibodies. Therefore, protein targets for Tyr-Tyr formation in vivo as well the protein residues involved remain under investigation.

In the case of cross-links involving protein-Trp residues, knowledge is even more limited. In fact, the potential formation of ditryptophan cross-links (Trp-Trp) in proteins has been largely disregarded in the literature. In 2010, we presented MS/MS evidence that the covalent dimer of the enzyme human superoxide dismutase 1 (hSOD1), produced during its bicarbonate-dependent peroxidase activity, was composed of two hSOD1 monomers bound by a Trp-Trp cross-link (hSOD1Trp32-Trp32hSOD1). ${ }^{19}$ Subsequent to this publication, a number of reports described the formation of Trp-Trp cross-links during peptide and protein oxidation, by a variety of oxidizing systems. ${ }^{20-25}$ Thus, the time has come to summarize these studies, emphasizing the challenges to characterize Trp-Trp cross-links and their potential roles in protein dysfunction and aggregation.

\section{Oxidation of Protein-Trp Residues}

The characterization of the oxidation products of protein-Trp residues poses difficulties for two major reasons. First, the indole moiety of Trp residues possess multiple sites for attack by oxidants and radicals, giving rise to many oxidized products (Figure 1). Second, the frequency of Trp in proteins is low (approximately 1\%), compared with other aromatic residues, such as Tyr (approximately $3-4 \%)$. The most frequently characterized oxidation products of protein-Trp residues have been proteintryptophanyl radicals (protein-Trp ${ }^{\bullet}$ ) and protein-bound products, such as tryptophan hydroperoxide (Trp-OOH), hydroxy-tryptophan (Trp-OH), nitro-tryptophan (Trp- $\mathrm{NO}_{2}$ ) $N$-formyl-kynurenine and kynurenine (Figure 1). ${ }^{14,19,26-30}$
On the other hand, Trp residues are the strongest UV chromophore in proteins, rendering diverse products through a rich photochemistry involving both protein-Trp ${ }^{\circ}$ and ${ }^{1} \mathrm{O}_{2}$-mediated pathways (Figure 1). ${ }^{31,32}$

Despite the low frequency of Trp residues in proteins, they have a unique potential to interact with other proteins and cellular structures. ${ }^{29,33,34}$ These interactions will likely change upon Trp oxidation with marked consequences to cellular homeostasis. Furthermore, the oxidation of Trp residues may also lead to protein dimerization, oligomerization and aggregation, disrupting cellular proteostasis. ${ }^{35,36}$ These consequences, among others, maintain the interest in the identification of the protein-Trp residue oxidation products. Newly identified products include glycinyl radical (Gly*) and related products ${ }^{14}$ and Trp-Trp cross-links (Figure 1).

\section{Early Reports on Trp-Trp Cross-Links}

The interest in investigating the ability of the Trp-Trp cross-link to impose conformational constraints on peptide scaffolds, led to their chemical synthesis and characterization some years ago. ${ }^{37,38}$ The chosen method was trifluoroacetic acid-promoted dimerization of tryptophan residues to a 2,2 ' indolylindone residue, followed by oxidation to 2,2'-biindoles (indole atom numbering is shown in Figure 1). This method produced high yields of dimeric peptides with the cross-link forming between $\mathrm{C} 2-\mathrm{C} 2$ ' of each Trp residue of the monomers.

Around the same time, there was a renewed interest in the enzyme superoxide dismutase 1 (SOD1) due to the discovery that mutations in this enzyme were associated with familial amyotrophic lateral sclerosis (ALS), a fatal neurodegenerative disease. ${ }^{39} \mathrm{SOD} 1$ is one of the most important antioxidant defenses because it efficiently catalyzes the dismutation of superoxide radical anion. ${ }^{40}$ However, the enzyme also displays other activities, such as its bicarbonate-dependent peroxidase activity, which received considerable interest in the literature. ${ }^{41-45}$ Kalyanamaran and co-workers ${ }^{46-48}$ demonstrated that this activity resulted in covalent dimerization and further oligomerization of the human enzyme (hSOD1). These authors also demonstrated that the covalent dimerization of hSOD1 was completely dependent on the oxidation of its single, solvent-exposed Trp residue (Trp32), by the enzymatically produced carbonate radical $\left(\mathrm{CO}_{3}{ }^{\circ}\right)$, to render the enzyme-derived radical (hSOD1Trp32 ${ }^{\circ}$. They also showed that $N$-formyl-kynurenine and kynurenine were present in oxidized hSOD1 and suggested that these oxidation products of Trp (Figure 1) were the precursors of the covalent cross-link. Nonetheless, the covalent hSOD1 dimer was not isolated nor was the structure determined. ${ }^{46-48}$ 


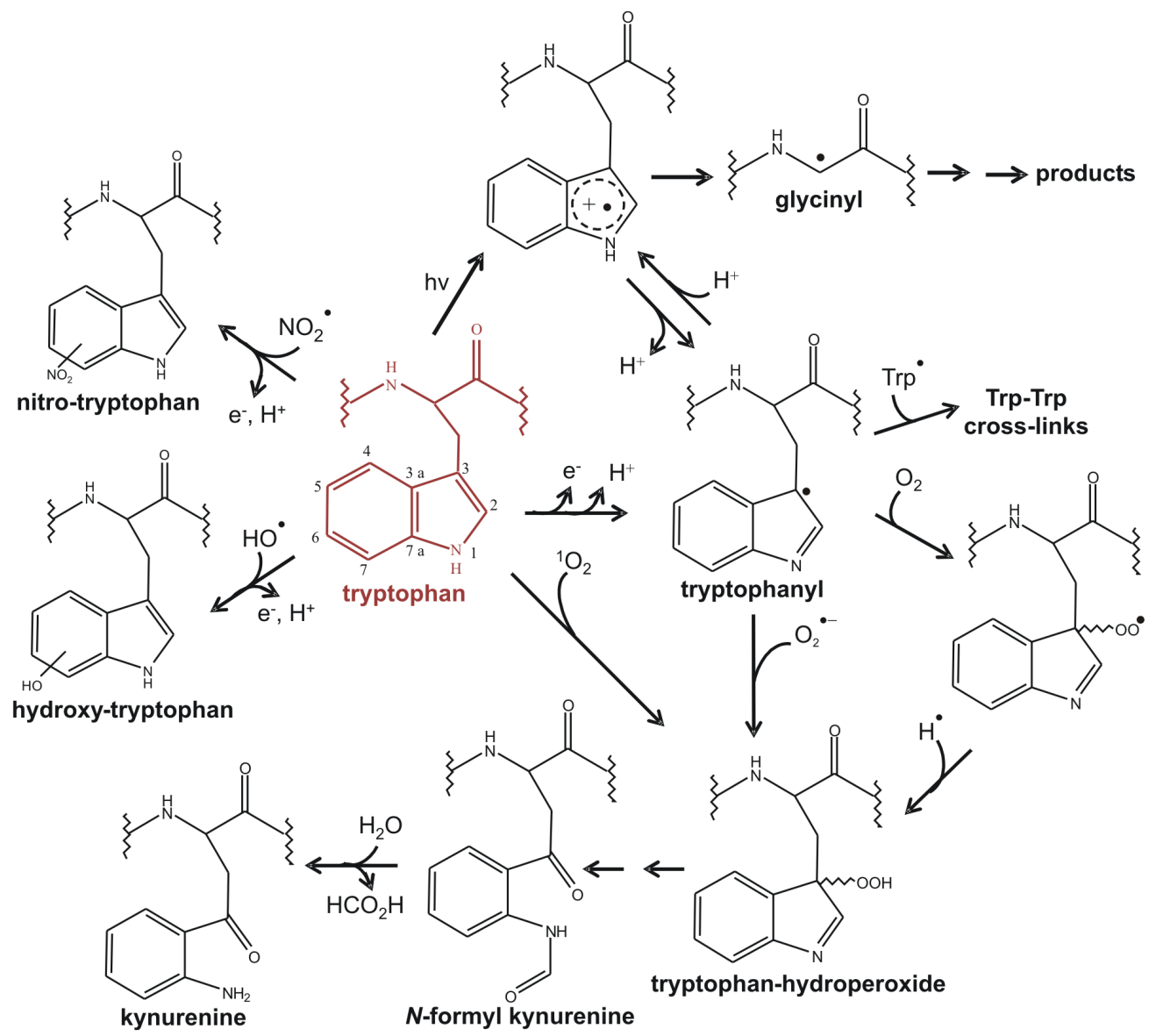

Figure 1. Some of the characterized products of the oxidation of protein-Trp residues. ${ }^{14,19,26-32}$

At about the same time, we were also investigating the bicarbonate-dependent peroxidase activity of hSOD1, and decided to characterize the covalent dimer. ${ }^{44}$ Towards this goal, we incubated hSOD1 $(10 \mu \mathrm{M})$ with $1 \mathrm{mM} \mathrm{H}_{2} \mathrm{O}_{2}$ in $200 \mathrm{mM} \mathrm{NaHCO} / \mathrm{CO}_{2}$ (equilibrated with $50 \% \mathrm{CO}_{2}$ balanced with air) buffer containing $100 \mu \mathrm{M}$ diethylene triamine pentaacetic acid (DTPA) (pH 7.4), with stirring for $2 \mathrm{~h}$ at room temperature $\left(25 \pm 2{ }^{\circ} \mathrm{C}\right)$, and obtained considerable yield of the hSOD1 covalent dimer (about 50\% of the enzyme dimerized). ${ }^{19}$ The dimer was isolated from the oxidized monomers by size exclusion chromatography, digested with trypsin in $\mathrm{H}_{2} \mathrm{O}$ or $\mathrm{H}_{2} \mathrm{O}^{18}$ and both hydrolysates were submitted for ESI-Q-TOF (electrospray ionization quadrupole time-of-flight) MS/MS analyses. The results showed that the peptide containing the cross-link cleaved into a great extent during MS/MS fragmentation, producing an apparently non-modified $\operatorname{Trp}$ residue and a Trp residue missing $2 \mathrm{H}$ atoms. Based on all the obtained results and on the literature, we proposed that the covalent Trp-Trp cross-link was likely occurring between N1-C3 of each Trp residue of the hSOD1 monomers (Figure 2) ${ }^{19}$ Indeed, dimer formation was dependent on hSOD1Trp production. Calculations and experimental evidence had shown that Trp' has higher spin densities at $\mathrm{C} 3$ and $\mathrm{N} 1 .{ }^{49}$ Additionally, a $\mathrm{C}-\mathrm{N}$ bond was more consistent with a higher susceptibility of the cross-link to cleave under the MS/MS conditions than a $\mathrm{C}-\mathrm{C}$ bond. This study provided the first clear evidence for the formation of a Trp-Trp cross-link in a protein by radical mechanisms, although the structure of the dimer was hypothesized, not characterized.

Later, the involvement of radical mechanisms was further confirmed. We showed that the nitroxide, tempol, recombined with the hSOD1Trp32 and inhibited the covalent dimerization of hSOD1 in vitro ${ }^{50}$ and also apparently, in vivo. ${ }^{51}$ Additionally, we confirmed that mutation of Trp32 to Phe32 inhibited the covalent dimerization and non-amyloid aggregation of hSOD1. ${ }^{36}$ Since the Trp32 residues are unique to simian SOD1s, their oxidation to Trp ${ }^{\circ}$ and recombination to Trp-Trp may play a role in the pathogenic mechanism of ALS.

\section{Trp-Trp Cross-Links as Novel Products of Protein Oxidation}

A number of reports from different researchers followed, demonstrating the formation of Trp-Trp cross-links in protein 
2<smiles>O=S(=O)(O)Cc1c[nH]c2ccccc12</smiles>

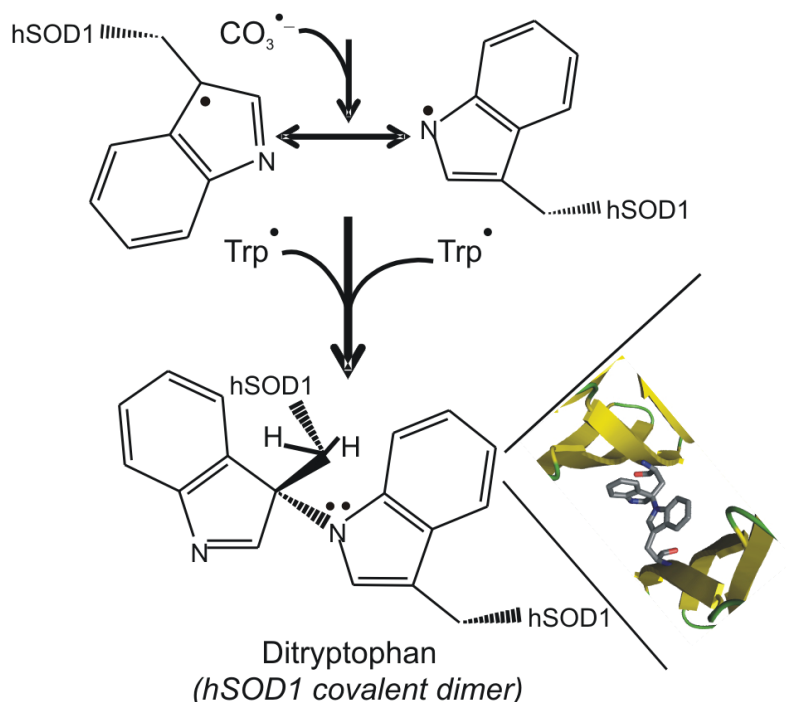<smiles>CC[C@]1(C)C=Nc2ccccc21</smiles>

Tryptophan $(-2 \mathrm{H})$

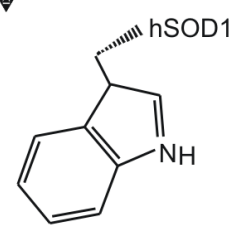

Tryptophan

Figure 2. Schematic representation of the mechanism proposed for hSOD1 dimerization during its bicarbonate-dependent peroxidase activity. This scheme also illustrates the fragmentation and rearrangement of the hSOD1Trp-TrphSOD1 dimer during MS/MS analysis. The inset shows a stereochemical view of the ditryptophan cross-link in the hSOD1 structure. The figure was adapted from reference 19 with permission.

and peptides mostly by radical mechanisms. The oxidation of peptides containing Trp and Tyr residues by high-energy UV laser pulses produced peptide-Trp• and peptide-Tyr, which recombined to produce Trp-Trp, Tyr-Tyr and Trp-Tyr cross-links, in the latter case by irradiation of mixtures of Trp- and Tyr-containing peptides. ${ }^{20}$

In another example, we treated the enzyme lysozyme with enzymatically- or photolytically-generated $\mathrm{CO}_{3}{ }^{-} \cdot{ }^{21}$ This resulted in oxidation of lysozyme at Trp28 (lysozymeTrp28),

which dimerized to form lysozymeTrp28-Trp28lysozyme, and inactivation and aggregation of the enzyme. The lysozymeTrp28-Trp28lysozyme dimer also formed when the enzyme was treated with UVC light for longer times than those used to generate the $\mathrm{CO}_{3}{ }^{-}{ }^{-}$from carbonatotetramminecobalt(III) complex photolysis (1 min) (Figure 3). ${ }^{21}$ Additionally, when lysozyme was treated with $\mathrm{CO}_{3}{ }^{-}$generated by the bicarbonate-dependent peroxidase activity of hSOD1, a Trp-Trp cross-linked heterodimer was produced (lysozymeTrp28-Trp32hSOD1) in parallel with lysozyme homodimer formation. Similar to what was observed with the hSOD1Trp32-Trp32hSOD1 dimer hydrolysates, the dimeric peptides of lysozyme cleaved during MS/MS fragmentation, producing an apparently non-modified Trp residue and a Trp residue missing $2 \mathrm{H}$ atoms (Figure 3). This characteristic led us to suggest that lysozyme dimer and heterodimer bind through a Trp-Trp cross-link between C3-N1 of the Trp residues of each monomer. In this study, we also made it clear that lysozymeTrp $28^{\circ}$ radical decayed by two competitive pathways, reaction with molecular oxygen to produce lysozyme- $N$-formylkynurenine, and reaction with another lysozymeTrp $28^{\circ}$ to produce the lysozymeTrp28-Trp28lysozyme dimer (Figure 1). ${ }^{21}$ Accordingly, the reaction of tryptophanyl radicals with molecular oxygen is not particularly rapid $\left(\mathrm{k} \leq 5 \times 10^{6} \mathrm{M}^{-1} \mathrm{~s}^{-1}\right),{ }^{52}$ whereas radical recombination reactions are close to the diffusion-controlled limit. Still, a high flux of protein-Trp is necessary to produce dimers because the rate of recombination reactions depends on the square of the radical concentration (Figure 1). It was also emphasized that the dimers produced by radical mechanisms were different from those first synthesized through the acid-promoted dimerization of Trp residues. ${ }^{21}$ Interestingly, earlier studies had proposed formation of lysozyme dimers bound by Trp-Trp cross-links upon treatment of the enzyme with a generator of peroxyl radicals, but the residues involved in the cross-links were not determined. ${ }^{53}$

Further evidence for Trp-Trp crosslinks comes from studies with bovine $\alpha$-crystallins submitted to anaerobic irradiation (330-390 nm) in the presence of kynurenic acid. ${ }^{22}$ This treatment led to the formation of both Trp-Trp and Tyr-Tyr cross-links. Alpha-crystallins contain three Trp residues (Trp9 in $\alpha$ A-crystallin and Trp9 and Trp60 in $\alpha \mathrm{B}$-crystallin), and MS evidence for Trp-Trp cross-links (i.e., detection of peptides with a $-2.017 \mathrm{Da}$ mass modification) was found for all three Trp residues. The authors ${ }^{22}$ proposed that the triplet state of kynurenic acid abstracts electrons from Trp and Tyr residues of the proteins, rendering the corresponding radicals that led to protein oligomerization and aggregation. 
(a)

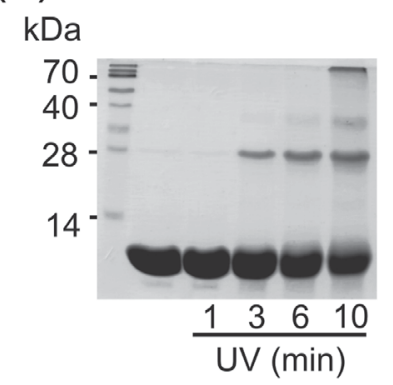

(b)

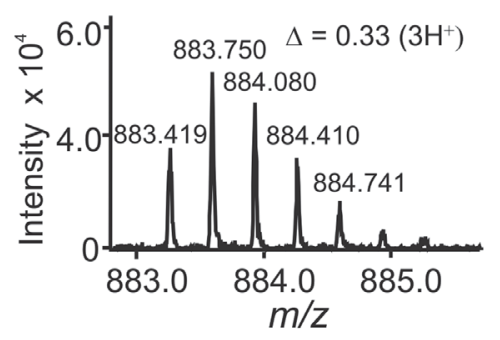

(c)

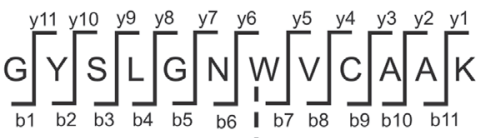

$$
\begin{aligned}
& \text { I }-2 \mathrm{H} \\
& \text { G Y S L G N W V CAAK }
\end{aligned}
$$

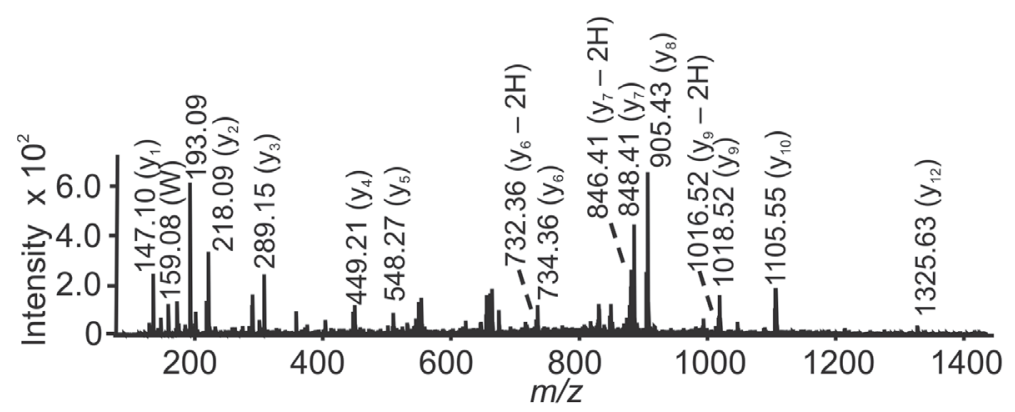

Figure 3. Time-dependent dimerization of lysozyme upon UV irradiation (a) and MS/MS characterization of the produced dimer (b) and (c). (a) Representative SDS-PAGE analysis of the time-dependent lysozyme dimerization and aggregation in samples of lysozyme (0.14 mM) irradiated with UV light (254 nm; radiance of $6.3 \mathrm{~mW} \mathrm{~cm}^{-2}$ ) for the specified times in phosphate buffer $(20 \mathrm{mM})$ containing DTPA $(0.1 \mathrm{mM})$, $\mathrm{pH} 7.0$. Aliquots corresponding to $30 \mu \mathrm{g}$ protein were removed and analyzed by SDS-PAGE. The gel was stained with Coomassie Blue; (b) nano-ESI-Q-TOF-MS and (c) MS/MS analysis of the dimeric tryptic peptide ${ }^{(22}$ GYSLGNWVCAAK $\left.{ }^{33}\right)_{2}$ obtained from lysozyme treated with UV light for 10 min. The MS/MS sequencing of the peak at $m / z$, 883.41 , which corresponds to the peptide ( ${ }^{22}$ GYSLGNWVCAAK $\left.{ }^{33}\right)_{2}$ (monoisotopic mass $2647.24 \mathrm{Da}$ ) with 3 charges is shown in (c) and its MS is shown in (b). The lysozyme dimer was isolated from the enzyme irradiated for $10 \mathrm{~min}$ as shown in (a); the samples were applied in 8 gel lanes, and the spots (at approximately $28 \mathrm{kDa}$ ) were excised from the gel, digested with trypsin, and subjected to ESI-Q-TOF-MS/MS analysis. Reprinted from reference 21 with permission.

More recently, oxidation of the enzyme glucose 6-phosphate dehydrogenase initiated by peroxyl radicals, or by photo-sensitized Rose Bengal, has been comprehensively compared. ${ }^{54}$ This study showed inactivation of the enzyme and the formation of various cross-links between Tyr-Tyr and Trp-Tyr residues, depending on the oxidizing system. The photo-sensitization of Rose Bengal produces ${ }^{1} \mathrm{O}_{2}$, which led to the formation of Tyr276-Tyr284, Tyr451-Tyr461 and Trp 203-Tyr207 cross-links. On the other hand, peroxyl radicals promoted the formation of Tyr276-Tyr284, Tyr451-Tyr461 and Trp328-Tyr284 cross-links. Since protein hydrolysis has been performed in solution, it was not possible to determine whether inter- or intra-molecular cross-links were produced. The fact that most of the cross-linked residues are proximal suggests that several intra-molecular cross-links were formed. By structural analyses, the authors concluded that the cross-links form from residues that are proximal, with at least one of them surface-exposed. Although Trp-Trp cross-links were not detectable, this study is interesting because it showed Trp-Tyr cross-links in proteins and confirmed the formation of protein-protein cross-links by radical mechanisms. ${ }^{21}$

In contrast with the above studies emphasizing the deleterious effects of cross-links to cells, a recent report has shown that the enzyme thioredoxin reductase contains an evolutionarily conserved and surface-exposed Trp residue (Trp114) that is quite sensitive to oxidation and may play a redox sensor-like function through oligomerization and crosslinking under oxidative stress conditions. ${ }^{23}$ Thioredoxin reductase exists as a homodimer in the native state, but forms tetramers through a cross-link between Trp114-Trp114 from two different enzyme dimers, upon oxidation. These covalently linked enzyme subunits significantly increase in extracts of cells treated with a pro-oxidant anticancer drug in parallel with increased cell death. These results suggested that the Trp114-Trp114 cross-link in thioredoxin reductase may represent a regulatory mechanism for the induction of cell death. ${ }^{23}$ 


\section{On the Structure of Trp-Trp Cross-Links Produced by Radical Mechanisms}

Despite the increasing reports on the formation of Trp-Trp crosslinks in peptides and proteins oxidized by radical mechanisms, the structures of these cross-links remain unknown. As mentioned above, we suggested cross-linking through a bond between N1-C3 of each monomer based on indirect evidences. Up to now, Trp-Trp cross-links have been detected by indirect methodologies or at best, by MS/MS of protein hydrolysates, which provide limited structural information. Therefore, it would be interesting to develop a methodology to synthesize sufficient Trp-Trp for spectroscopic analysis; however, this has been a difficult task.

In contrast to Trp-Trp cross-links, the Tyr-Tyr cross-link is well-characterized, and the compound 3,3'-dityrosine is obtained in considerable yields, through the oxidation of Tyr by $\mathrm{H}_{2} \mathrm{O}_{2}$ catalyzed by horseradish peroxidase. ${ }^{16,55}$ Although the reduction potential of $\operatorname{Trp}^{\bullet}\left(\mathrm{E}^{\circ}=1.05 \mathrm{~V}\right)$ and $\mathrm{Tyr}^{\bullet}\left(\mathrm{E}^{0^{\prime}}=0.94 \mathrm{~V}\right)$ differ by $0.11 \mathrm{~V},{ }^{56} \mathrm{Trp}$ oxidation by $\mathrm{H}_{2} \mathrm{O}_{2}$ catalyzed by horseradish peroxidase or other heme peroxidases is quite inefficient. The high oxidation states of heme peroxidases (i.e.,

(a)
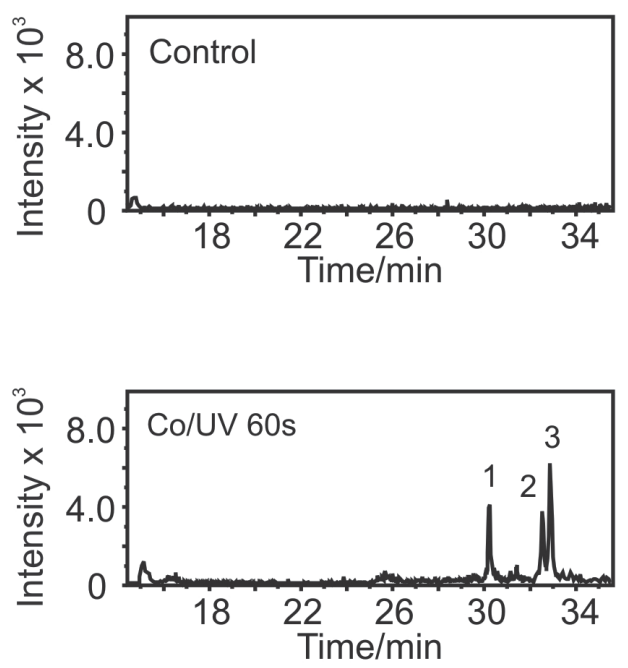

compounds I and II) have considerable redox potentials, but only compound I oxidizes Trp at a substantial rate. ${ }^{57}$ Consequently, the peroxidatic cycle of these enzymes discontinues, producing low yields of Trp. Indeed, we confirmed that horseradish peroxidase $/ \mathrm{H}_{2} \mathrm{O}_{2}$ barely oxidizes Trp, whereas it oxidizes Tyr to Tyr-Tyr almost quantitatively (unpublished results).

An alternative for synthesizing Trp-Trp cross-links from the oxidation of Trp or peptides-containing Trp could be through the use of $\mathrm{CO}_{3}{ }^{--}\left(\mathrm{E}^{\mathrm{o}^{\prime}}=1.78 \mathrm{~V}\right)$, due to its high reduction potential. ${ }^{21,58}$ While testing $\mathrm{CO}_{3}{ }^{-}$in the development of synthetic procedures, we treated $\operatorname{Trp}(1 \mathrm{mM})$ with $\mathrm{CO}_{3}{ }^{--}$generated from carbonatotetramminecobalt(III) complex photolysis, under conditions that produce approximately $0.13 \mathrm{mM} \mathrm{CO}_{3}{ }^{-} \cdot{ }^{-21}$ The spent reaction was analyzed by LC-MS/MS and we were surprised to observe three peaks with $\mathrm{m} / \mathrm{z}$ values of 407.17 , which correspond to Trp-Trp and were not present in the control (Figure 4). These results indicated that three Trp-Trp isomers were produced on treatment of $\operatorname{Trp}(1 \mathrm{mM})$ with photolitically generated $\mathrm{CO}_{3}^{-{ }^{-}}(0.13 \mathrm{mM})$.

In line with the above results, we learned at a recent meeting that Trp and Trp-containing peptides subjected to steady-state radiolysis, under anaerobic conditions,

(b)
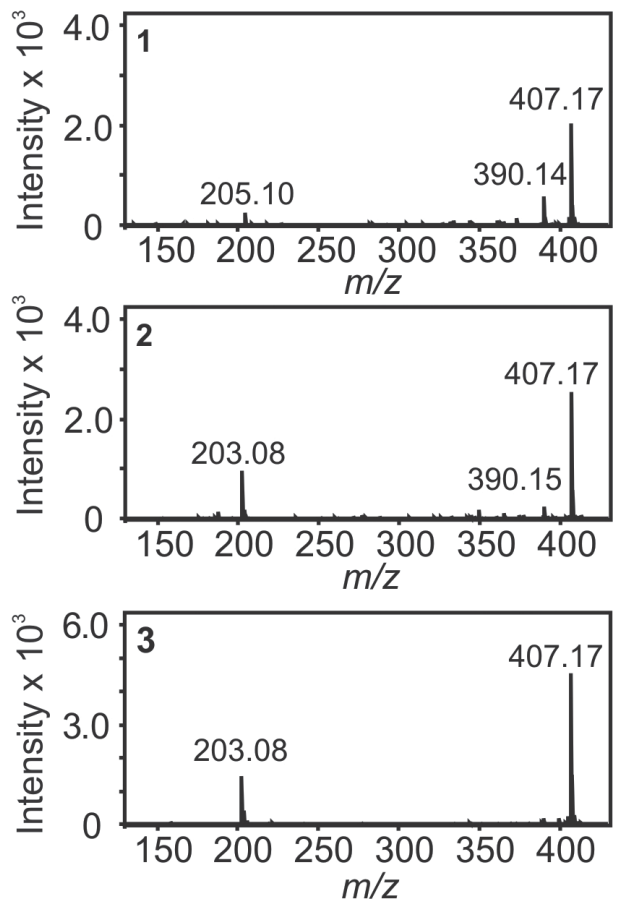

Figure 4. Characterization of ditryptophan crosslinks produced by treatmente of Trp with the $\mathrm{CO}_{3}{ }^{--}$. Trp (1 mM), DTPA (0.1 mM) and the carbonatotetramminecobalt(III) complex $(4 \mathrm{mM})$ in phosphate buffer $(20 \mathrm{mM}), \mathrm{pH} 7.0$ were irradiated for 1 min with UV light at a wavelength of $254 \mathrm{~nm}$ (radiance of $6.3 \mathrm{~mW} \mathrm{~cm}^{-2}$ ) (abbreviated as Co/UVC). ${ }^{21}$ The control corresponds to the same solution without irradiation. (a) Extraction ion chromatogram corresponding to ditryptophan ( $\mathrm{m} / \mathrm{z} 407.17$ with one charge); (b) HPLC-ESI-Q-TOF-MS/MS analysis of the ion with $\mathrm{m} / \mathrm{z} 407.17$ corresponding to peaks 1,2 and 3 shown in (a) as specified. 
show a dose dependent consumption of parent compounds and the formation of up to 4 isomeric Trp-Trp dimers. ${ }^{25}$ This study was just published. ${ }^{59}$ Concomitantly, other investigators ${ }^{60}$ showed that UV-A photolysis sensitized by kynurenic acid of $N$-acetyl-tryptophan under anaerobic conditions led to the formation of three types of Trp-Trp dimers (characterized by different UV spectra and MS fragmentation patterns) and possibly their diasteroisomers. These very recent results pose even more difficulties to the challenge of characterizing the structures of Trp-Trp cross-links produced in proteins by radical mechanisms.

The indolyl radical possess considerable spin density at C4 (0.19) and C6 (0.15) in addition to C3 (0.48) and N1 (0.23). ${ }^{49}$ Therefore, radical dimerization can potentially occur at all of these sites, some of which resulting in different stereoisomers. Indeed, the reaction of $\mathrm{N}$-acetylL-tryptophan amide with $\mathrm{NO}_{2}{ }^{\circ}$, which oxidizes Trp to Trp ${ }^{\bullet}$ and recombines with it, renders Trp nitration at positions 4, 6, 7 and $\mathrm{N} 1$ of the indole ring. ${ }^{28,29}$ This is in contrast to the products formed from the reaction of Tyr with $\mathrm{NO}_{2}{ }^{\circ}$, which are apparently limited to 3-nitro-tyrosine and 3,3'-dityrosine, ${ }^{61,62}$ despite the considerable spin density of the $\mathrm{Tyr}^{*}$ at $\mathrm{C} 1(0.39)$ and $\mathrm{O}(0.17)$, in addition to $\mathrm{C} 3(0.25)$ and $\mathrm{C} 5(0.26) .{ }^{63}$ The fact that C3 of Trp is not nitrated by $\mathrm{NO}_{2} \cdot$ may indicate steric constraints. Such a possibility argues against a Trp-Trp cross-link bound by a C3-C3 linkage or is in favor of a strained bond that can be cleaved under MS/MS conditions, as has been observed. On the other hand, the possibility of a Trp-Trp dimer linked through a C3-C4 linkage has been suggested based on MS/MS analysis of a complex mixture, resulting from the oxidation of $\operatorname{Trp}(5 \mathrm{mM})$, by a strong Fenton system $\left[\mathrm{H}_{2} \mathrm{O}_{2}(25 \mathrm{mM}) / \mathrm{FeCl}_{2}(0.1 \mathrm{mM})\right]$ in bicarbonate buffer, pH 7.4. ${ }^{64}$ Among the products, the authors ${ }^{64}$ identified a Trp-Trp dimer and also a 6-(3-methyl-indole) tryptophan adduct, which could be a fragmentation product of a Trp-Trp dimer. In this case, the dimer would be the 3,4'-ditryptophan. The fact is that the full spectroscopic characterization of Trp-Trp cross-links remains to be performed and radiolysis of Trp-containing peptides may provide sufficient amounts of dimers to this purpose.

Davies and co-workers ${ }^{25,59}$ showed the formation of multiple Trp-Trp dimers also in lysozyme submitted to oxidants, particularly to $\mathrm{CO}_{3}{ }^{-}$, and digested by alkaline hydrolysis to release the cross-links. These results indicate that different Trp-Trp cross-links can be produced in proteins, despite the constraints imposed by the polypeptide chain and the three dimensional protein structure. Whether this situation holds for all proteins containing the Trp-Trp linkage remains to be investigated.

\section{Conclusions and Perspectives}

Trp-Trp cross-links produced by recombination of protein-Trp• have been overlooked in the literature until recently. However, as summarized here, the detection of Trp-Trp cross-links in proteins exposed to different oxidants has been, recently, reported in the literature more frequently. The great advances in the sensitivity of MS/MS spectrometers have been a major factor in detection of Trp-Trp cross-links. Further progress will depend on the development of bioinformatics tools for analysis of LC-MS/MS proteomic data related to protein-protein cross-links, particularly from biological samples. Since different Trp-Trp cross-links can be produced by radical mechanisms (Figure 4), ${ }^{25,59,60}$ it will be important to fully characterize them. Likewise, their properties and possible predominance under different circumstances should also be investigated. The formation of Trp-Trp cross-links in cells and organisms has yet to be completely established, but it is likely to occur. Indeed, extracts of cells, which were pre-treated with an anticancer compound, displayed increased levels of Trp-Trp cross-linked thioredoxin reductase dimers, although MS evidence could not be obtained. ${ }^{23}$ Additionally, other authors, while developing a new algorithm to analyze post-translational modifications of proteins from MS/MS databases of human cataracts, identified Trp-containing peptides with a mass change of $-2.017 \mathrm{Da}$, which is suggestive of a Trp-Trp cross-link. ${ }^{65}$ We previously suggested that among the one-electron oxidants produced under physiological conditions, $\mathrm{CO}_{3}^{-{ }^{-}}$ was the one most likely to attack protein-Trp residue to produce protein-Trp* in yields high enough to favor their recombination. ${ }^{21}$ Such a prediction is consistent with the recently published work by Davies and co-workers..$^{59}$ We also suggested that environmental factors, such as UV light and solar irradiation, were also likely to favor Trp-Trp formation, ${ }^{21}$ also in line with recent studies. ${ }^{22,24,60}$ These recent studies argues for the importance of Trp-Trp and Trp-Tyr cross-links in protein dysfunction, oligomerization and aggregation, demanding further studies on the subject.

\section{Acknowledgments}

This work was supported by Fundação de Amparo à Pesquisa do Estado de São Paulo (FAPESP), grant 2013/07937-8 (CEPID Redoxoma); Conselho Nacional de Desenvolvimento Científico Tecnológico (CNPq), grants 573530/2008-4 and 152693/2016-5; and Pro-Reitoria de Pesquisa da Universidade de São Paulo (PRPUSP), grant 2011.1.9352.1.8. 


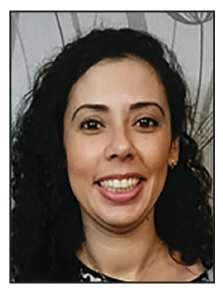

Veronica Paviani graduated in Pharmacy (2010) and obtained the Master (2013) and the PhD degree (2016) in Biochemistry. Currently, she is a postdoctoral fellow at the Department of Biochemistry, Chemistry Institute, USP, where she employs mass spectrometry, among other techniques, to characterize oxidative modifications of proteins in vitro and in biological samples.

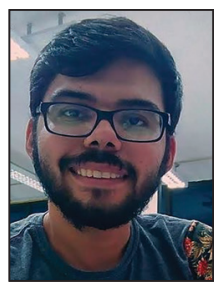

Gabriel Tiago Galdino is an undergraduate research student of the Chemistry Institute (IQ-USP) and he is working in the elucidation of posttranslational modifications of tryptophan since 2016. He is now completing the Molecular Sciences course and has experience in organic synthesis since high school when he developed a new larvicide from the cashew shell nut oil. He is a two-times champion of the Brazilian Science and Engineering Fair (FEBRACE) and obtained the third place in the Intel-International Science and Engineering Fair (Intel ISEF 2013), the biggest science competition for high school students in the world.

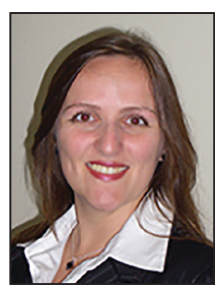

Janaina N. dos Prazeres is graduated in Biological Sciences at Universidade Estadual de Campinas (UNICAMP) in 1999, and obtained the Master and PhD degrees in 2002 and in 2006, respectively, in the Food Science Institute at the same University. Her experience includes protein biochemistry and enzyme expression in bacteria and yeast. Since 2009, she works as a biochemical specialist at Instituto de Química, Universidade de São Paulo (USP). Her current focus is analytical biochemistry, working with a wide variety of techniques such as liquid chromatography, $2 D$ electrophoresis and mass spectrometry. She also has experience in working with laboratory animals.

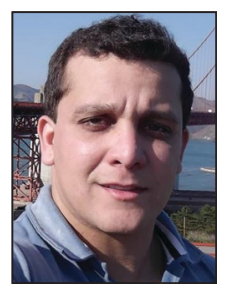

Raphael $\boldsymbol{F}$. Queiroz received the bachelor's degree in Pharmacy 10 years ago from Universidade Federal de Alfenas, Minas Gerais, Brazil. He completed the PhD in Biochemistry in 2012 at the Instituto de Química, Universidade de São Paulo, São Paulo, Brazil. Since then, he is an Associate Professor of Pharmacology and Biochemistry at the Medical School of the Universidade do Sudoeste da Bahia. Currently, his research interests are focused on redox processes related to infection and inflammation, and pharmacology of natural products.

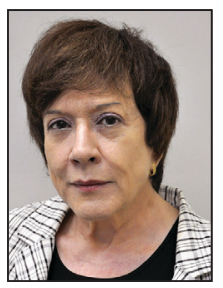

Ohara Augusto received her undergraduate (BSc in Chemistry in 1972) and graduate (PhD in Biochemistry in 1975) titles at the Instituto de Química, Universidade de São Paulo (IQ-USP) and did postdoctoral work at the University of California (Berkeley, 1980) and University of California (San Francisco, 1981-1982). She is Full Professor of Biochemistry at the IQ-USP since 1993. Her research interests have always been focused in the understanding of the multiple roles offree radicals and oxidants in physiology and pathophysiology. She has received several prizes and honors for her contributions to redox biochemistry.

\section{References}

1. Winterbourn, C. C.; Nat. Chem. Biol. 2008, 4, 278.

2. Jones, D. P.; Sies, H.; Antioxid. Redox Signaling 2015, $23,734$.

3. Davies, M. J.; Fu, S.; Wang, H.; Dean, R. T.; Free Radical Biol. Med. 1999, 27, 1151.

4. Davies, M. J.; Biochim. Biophys. Acta 2005, 1703, 93.

5. Davies, M. J.; Dean, R. T.; Radical-Mediated Protein Oxidation: From Chemistry to Medicine; Oxford University Press: Oxford/ New York, 1997.

6. Rhee, S. G.; Chae, H. Z.; Kim, K.; Free Radical Biol. Med. 2005, 38, 1543.

7. Rhee, S. G.; Woo, H. A.; Kil, I. S.; Bae, S. H.; J. Biol. Chem. 2012, 287, 4403.

8. Winterbourn, C. C.; Hampton, M. B.; Free Radical Biol. Med. 2008, 45, 549.

9. Berlett, B. S.; Stadtman, E. R.; J. Biol. Chem. 1997, 272, 20313.

10. Dalle-Donne, I.; Rossi, R.; Colombo, R.; Giustarini, D.; Milzani, A.; Clin. Chem. 2006, 52, 601.

11. Grune, T.; Jung, T.; Merker, K.; Davies, K. J. A.; Int. J. Biochem. Cell Biol. 2004, 36, 2519.

12. Reeg, S.; Grune, T.; Antioxid. Redox Signaling 2015, $23,239$.

13. Schöneich, C.; J. Pharm. Pharmacol. 2017, DOI 10.111/ php. 12688.

14. Haywood, J.; Mozziconacci, O.; Allegre, K. M.; Kerwin, B. A.; Schöneich, C.; Mol. Pharmaceutics 2013, 10, 1146.

15. Annibal, A.; Colombo, G.; Milzani, A.; Dalle-Donne, I.; Fedorova, M.; Hoffmann, R.; J. Chromatogr. B 2016, 1019, 147.

16. DiMarco, T.; Giulivi, C.; Mass Spectrom. Rev. 2007, 26, 108.

17. Fu, S.; Dean, R.; Southan, M.; Truscott, R.; J. Biol. Chem. 1998 , 273, 28603. 
18. Hensley, K.; Maidt, M. L.; Yu, Z.; Sang, H.; Markesbery, W. R.; Floyd, R. A.; J. Neurosci. 1998, 18, 8126.

19. Medinas, D. B.; Gozzo, F. C.; Santos, L. F. A.; Iglesias, A. H.; Augusto, O.; Free Radical Biol. Med. 2010, 49, 1046.

20. Leo, G.; Altucci, C.; Bourgoin-Voillard, S.; Gravagnuolo, A. M.; Esposito, R.; Marino, G.; Costello, C. E.; Velotta, R.; Birolo, L; Rapid Commun. Mass Spectrom. 2013, 27, 1660.

21. Paviani, V.; Queiroz, R. F.; Marques, E. F.; Di Mascio, P.; Augusto, O.; Free Radical Biol. Med. 2015, 89, 72.

22. Sherin, P. S.; Zelentsova, E. A.; Sormacheva, E. D.; Yanshole, V. V.; Duzhak, T. G.; Tsentalovich, Y. P.; Phys. Chem. Chem. Phys. 2016, 18, 8827.

23. Xu, J.; Eriksson, S. E.; Cebula, M.; Sandalova, T.; Hedström, E.; Pader, I.; Cheng, Q.; Myers, C. R.; Antholine, W. E.; Nagy, P.; Hellman, U.; Selivanova, G.; Lindqvist, Y.; Arnér, E. S. J.; Cell Death Dis. 2015, 6, e1616.

24. Paviani, V.; Augusto, O.; Free Radical Biol. Med. 2016, 100, S19.

25. Carroll, L.; Pattison, D. I.; Davies, J.; Anderson, R. F.; LopezAlarcon, C.; Davies, M. J.; Free Radical Biol. Med. 2016, 100, S20.

26. Plowman, J. E.; Deb-Choudhury, S.; Grosvenor, A. J.; Dyer, J. M.; Photochem. Photobiol. Sci. 2013, 12, 1960.

27. Simat, T. J.; Steinhart, H.; J. Agric. Food Chem. 1998, 46, 490.

28. Sala, A.; Nicolis, S.; Roncone, R.; Casella, L.; Monzani, E.; Eur. J. Biochem. 2004, 271, 2841.

29. Yamakura, F.; Ikeda, K.; Nitric Oxide 2006, 14, 152.

30. Ehrenshaft, M.; Deterding, L. J.; Mason, R. P.; Free Radical Biol. Med. 2015, 89, 220.

31. Pattison, D. I.; Rahmanto, A. S.; Davies, M. J.; Photochem. Photobiol. Sci. 2011, 11, 38.

32. Ronsein, G. E.; de Oliveira, M. C. B.; de Medeiros, M. H. G.; Di Mascio, P.; J. Am. Soc. Mass Spectrom. 2009, $20,188$.

33. Ge, C.; Georgiev, A.; Öhman, A.; Wieslander, Å.; Kelly, A. A.; J. Biol. Chem. 2011, 286, 6669.

34. Fernández-Vidal, M.; Jayasinghe, S.; Ladokhin, A. S.; White, S. H.; J. Mol. Biol. 2007, 370, 459.

35. Taylor, D. M.; Gibbs, B. F.; Kabashi, E.; Minotti, S.; Durham, H. D.; Agar, J. N.; J. Biol. Chem. 2007, 282, 16329.

36. Coelho, F. R.; Iqbal, A.; Linares, E.; Silva, D. F.; Lima, F. S.; Cuccovia, I. M.; Augusto, O.; J. Biol. Chem. 2014, 289, 30690.

37. Dinh, T. D.; Van Vranken, D. L.; J. Pept. Res. 1999, 53, 465.

38. Stachel, S. J.; Habeeb, R. L.; Van Vranken, D. L.; J. Am. Chem. Soc. 1996, 118, 1225.

39. Rosen, D. R.; Nature 1993, 364, 362.

40. Fridovich, I.; J. Biol. Chem. 1997, 272, 18515.

41. Liochev, S. I.; Fridovich, I.; Proc. Natl. Acad. Sci. U. S. A. 2004, 101, 743.

42. Elam, J. S.; Malek, K.; Rodriguez, J. A.; Doucette, P. A.; Taylor, A. B.; Hayward, L. J.; Cabelli, D. E.; Valentine, J. S.; Hart, P. J.; J. Biol. Chem. 2003, 278, 21032.

43. Goss, S. P.; Singh, R. J.; Kalyanaraman, B.; J. Biol. Chem. 1999, 274, 28233.
44. Medinas, D. B.; Toledo Jr., J. C.; Cerchiaro, G.; do Amaral, A. T.; de Rezende, L.; Malvezzi, A.; Augusto, O.; Chem. Res. Toxicol. 2009, 22, 639.

45. Ranguelova, K.; Ganini, D.; Bonini, M. G.; London, R. E.; Mason, R. P.; Free Radical Biol. Med. 2012, 53, 589.

46. Zhang, H.; Andrekopoulos, C.; Joseph, J.; Chandran, K.; Karoui, H.; Crow, J. P.; Kalyanaraman, B.; J. Biol. Chem. 2003, 278, 24078.

47. Zhang, H.; Andrekopoulos, C.; Joseph, J.; Crow, J.; Kalyanaraman, B.; Free Radical Biol. Med. 2004, 36, 1355.

48. Zhang, H.; Joseph, J.; Crow, J.; Kalyanaraman, B.; Free Radical Biol. Med. 2004, 37, 2018

49. Walden, S. E.; Wheeler, R. A.; J. Phys. Chem. 1996, 100, 1530.

50. Queiroz, R. F.; Paviani, V.; Coelho, F. R.; Marques, E. F.; Di Mascio, P.; Augusto, O.; Biochem. J. 2013, 455, 37.

51. Linares, E.; Seixas, L. V.; dos Prazeres, J. N.; Ladd, F. V. L.; Ladd, A. A. B. L.; Coppi, A. A.; Augusto, O.; PLoS One 2013, 8, e55868.

52. Candeias, L. P.; Wardman, P.; Mason, R. P.; Biophys. Chem. 1997, 67, 229.

53. Arenas, A.; López-Alarcón, C.; Kogan, M.; Lissi, E.; Davies, M. J.; Silva, E.; Chem. Res. Toxicol. 2013, 26, 67.

54. Leinisch, F.; Mariotti, M.; Rykaer, M.; Lopez-Alarcon, C.; Hägglund, P.; Davies, M. J.; Free Radical Biol. Med. 2017, 112, 240.

55. Pichorner, H.; Metodiewa, D.; Winterbourn, C. C.; Arch. Biochem. Biophys. 1995, 323, 429.

56. DeFelippis, M. R.; Murthy, C. P.; Faraggi, M.; Klapper, M. H.; Biochemistry 1989, 28, 4847.

57. Jantschko, W.; Furtmüller, P. G.; Allegra, M.; Livrea, M. A.; Jakopitsch, C.; Regelsberger, G.; Obinger, C.; Arch. Biochem. Biophys. 2002, 398, 12.

58. Augusto, O.; Bonini, M. G.; Amanso, A. M.; Linares, E.; Santos, C. C. X.; de Menezes, S. L.; Free Radical Biol. Med. 2002, 32, 841.

59. Carroll, L.; Pattison, D. I.; Davies, J. B.; Anderson, R. F.; LopezAlarcon, C.; Davies, M. J.; Free Radical Biol. Med. 2017, 113, 132.

60. Sormacheva, E. D.; Sherin, P. S.; Tsentalovich, Y. P.; Free Radical Biol. Med. 2017, 113, 372.

61. Prütz, W. A.; Mönig, H.; Butler, J.; Land, E. J.; Arch. Biochem. Biophys. 1985, 243, 125.

62. Radi, R.; Acc. Chem. Res. 2013, 46, 550.

63. O’Malley, P. J.; MacFarlane, A. J.; Rigby, S. E. J.; Nugent, J. H. A.; Biochim. Biophys. Acta, Bioenerg. 1995, 1232, 175.

64. Domingues, M. R. M.; Domingues, P.; Reis, A.; Fonseca, C.; Amado, F. M. L.; Ferrer-Correia, A. J. V.; J. Am. Soc. Mass Spectrom. 2003, 14, 406.

65. Tsur, D.; Tanner, S.; Zandi, E.; Bafna, V.; Pevzner, P. A.; Nat. Biotechnol. 2005, 23, 1562.

Submitted: October 13, 2017

Published online: December 21, 2017 